\title{
POU Domain
}

National Cancer Institute

\section{Source}

National Cancer Institute. POU Domain. NCI Thesaurus. Code C13423.

The POU domain is a bipartite DNA binding domain recognized originally as a shared structural motif in the Pit-1, Oct-1/Oct-2, and Unc-86 transcription factors (POU). It is comprised by a C-terminal homeo domain, and an $\mathrm{N}$-terminal POU-specific domain, separated by a non-conserved linker. The POU-specific domain, like the homeo domain, is folded in a helix-turn-helix motif. 